\title{
Substrate mineralization stimulates focal adhesion contact redistribution and cell motility of bone marrow stromal cells
}

\author{
Elena V. Leonova, ${ }^{1}$ Keith E. Pennington, ${ }^{2}$ Paul H. Krebsbach, ${ }^{1,2}$ David H. Kohn ${ }^{1,2}$ \\ ${ }^{1}$ Department of Biologic and Materials Sciences, University of Michigan, Ann Arbor, Michigan 48109-1078 \\ ${ }^{2}$ Department of Biomedical Engineering, University of Michigan, Ann Arbor, Michigan 48109-2099
}

Received 3 June 2005; revised 13 October 2005; accepted 14 February 2006

Published online 30 June 2006 in Wiley InterScience (www.interscience.wiley.com). DOI: 10.1002/jbm.a.30786

\begin{abstract}
Understanding the mechanisms of substrate based control of cell function is critical to the design of biomaterials. Cells interact with their extracellular matrix through cell adhesion contacts. We have previously described the self assembly of bone-like mineral onto an organic template and have shown that these biomimetic surfaces lead to an increased volume fraction of bone regenerated in vivo. In the present study, we compared the distribution of cell adhesion contacts, cell spreading, and cell motility of murine bone marrow stromal cells (BMSC) on mineralized vs. nonmineralized substrates. We developed a new approach for quantification of cell-material interactions and demonstrated that cell adhesion contacts on mineralized substrates were distributed throughout the cell surface contacting the substrate, whereas on nonmineralized substrates cell adhesion contacts were present near the cell periphery.
\end{abstract}

We propose that mineralized substrates stimulate the predominant expression of fibrillar contacts, and nonmineralized substrates stimulate expression of focal adhesion contacts. Cell motility assays with colloidal gold demonstrated a statistically significant decrease in the average phagokinetic index of migrating cells on mineralized vs. nonmineralized substrates after $90 \mathrm{~min}$ of cell seeding. We propose that the physical-chemical properties of the substrate, altered by mineralization, cause expression of specific types of cell contacts and, as a result, modify molecular mechanisms responsible for cell spreading, motility, and possibly differentiation. (C) 2006 Wiley Periodicals, Inc. J Biomed Mater Res 79A: 263-270, 2006

Key words: mineralization; focal adhesion contacts; fibrillar contacts; cell motility; immunofluorescence

\section{INTRODUCTION}

A major challenge in tissue engineering is to produce materials that will regulate and control cell functions. The design of biomaterials should be based on understanding and quantifying the cellular reactions on natural and artificial extracellular substrates. ${ }^{1,2}$ Data demonstrating that surface properties of materials influence cellular attachment, proliferation, differentiation, and motility, support this proposal. ${ }^{3-5}$ However, the mechanisms by which cellular response is modulated by substrate properties are not completely understood. Model systems are therefore needed to enable systematic and quantitative analysis of cellular

Correspondence to: D.H. Kohn; e-mail: dhkohn@umich.edu Contract grant sponsor: NIH; contract grant numbers: R01 DE 013380 and R01 DE 015411

Contract grant sponsors: U.S. Army Research Laboratory and U.S. Army Research Office; contract grant number: DAAD 190310168

(C) 2006 Wiley Periodicals, Inc. reactions as functions of the physical and chemical properties of different substrates.

Materials used to study the basic mechanisms of cell-surface interactions must also be designed within the context of their long term clinical application. The biomaterials used in tissue engineering of bone must be biocompatible, degradable, mechanically robust, osteoconductive, and able to integrate with surrounding cells and tissues. ${ }^{6-9}$ Poly(lactic-co-glycolic acid) (PLGA) polymers have been used clinically for over thirty years, and are popular choices for a variety of tissue engineering applications. These polymers are biocompatible and biodegradable. ${ }^{10}$ The mechanical properties of PLGA can be increased by soaking in simulated body fluid (SBF) to nucleate and grow a layer of hydroxyapatite on the surface of the polymer. ${ }^{7}$ Mineralization also increases osteoconductivity of the substrate and enhances the ability of transplanted bone marrow stromal cells (BMSC) to regenerate bone in vivo. ${ }^{5,11}$ How a mineral layer on a synthetic polymer influences the contacting cells is not completely understood but, based on cell-extracellular matrix inter- 
actions, ${ }^{12-17}$ the mineral may modify cellular adhesion contacts directly interacting with its surface.

Cells interact with their extracellular matrix via specialized cell surface receptors, mostly concentrated in the cellular adhesion contacts. ${ }^{12-17}$ Receptors in cellular adhesion contacts not only mechanically couple the cell and extracellular matrix, but also serve as mechanosensors and play a major role in cellular signaling and communication. ${ }^{12,13,18-23}$ Cellular adhesion contacts are responsible for a cell's ability to adhere to a substrate, spread, and then migrate on the substrate. Spreading and migration are correlated with cytoskeleton reorganization and formation of new cellular contacts.

Bone marrow is a widely used source of multipotential and progenitor cells, and BMSC are potentially a source of cells for therapeutic use in bone regeneration. ${ }^{24-27}$ In vitro and in vivo function of BMSCs is enhanced on mineralized surfaces compared with their polymeric counterparts, both in $2 \mathrm{D}$ and $3 \mathrm{D} .{ }^{11} \mathrm{We}$ therefore hypothesized that the initial mechanism by which self-mineralization of a PLGA substrate alters biological function is an alteration in cell adhesion contacts. To determine the effect of mineralization on cell reaction, murine BMSCs were seeded on mineralized and nonmineralized PLGA films and the distribution of cellular contacts as well as cell motility was quantified. Based on the position of cell adhesion contacts relative to the cell center, fibrillar contacts were predominantly expressed on mineralized PLGA, whereas focal adhesion contacts were mostly expressed on PLGA. We propose that the physicalchemical properties of the substrate cause expression of specific types of cell contacts and, as a result, modify molecular mechanisms responsible for cell spreading, motility, and possibly differentiation.

\section{MATERIALS AND METHODS}

\section{Animals}

Animals used in this study were treated in accordance with the policies of the University Committee on Use and Care of Animals at the University of Michigan, which are consistent with NIH guidelines for the care and use of laboratory animals (NIH Publication No 85-23, Rev., 1985). Twenty eight C57/BL6 (Harlan, Sprague Dawley, Boyertown, PA) male mice, 6-weeks old, were used.

\section{Cell harvesting}

Mice were sacrificed, soaked in 70\% ethanol for $3 \mathrm{~min}$, and bones (femora and tibiae) were removed as quickly as possible, and placed in Hanks balanced salt solution (HBSS;
Invitrogen, Grand Island, NY). All tissues surrounding the bones were carefully removed and the epiphyses were dissected from each bone. The bone marrow was flushed using a $5-\mathrm{mL}$ syringe with a 21-gauge needle. The bone marrow from 2 to 4 animals was pooled together, and cells were gently separated by passing through a needle several times. Cells were centrifuged three times in HBSS. After the third rinse, HBSS was replaced with media and cells were seeded into 25-mL flasks and placed in a $\mathrm{CO}_{2}$ incubator.

\section{Tissue culture}

Cells were grown under the following conditions: $37^{\circ} \mathrm{C}$ at $5 \% \mathrm{CO}_{2}$ in $\alpha$-DMEM with $10 \%$ fetal bovine serum plus penicillin and streptomycin $(20 \mu / \mathrm{mL})$ (Invitrogen, Carlsbad, CA). Bone marrow stromal cells (BMSC) were collected and expanded using the plastic adherent technique. Cells were grown to $80 \%$ confluence, split 1:2 in $\alpha$-DMEM, and second passage cells were used in these experiments. Cells were seeded on poly(lactic-co-glycolic acid) (PLGA) films prepared on glass coverslips or on mineralized PLGA. Cells were fixed after $30 \mathrm{~min}, 45 \mathrm{~min}, 60 \mathrm{~min}, 90 \mathrm{~min}, 3,6$, or $24 \mathrm{~h}$ of incubation.

\section{PLGA casting and mineralization}

Two methods of PLGA casting were used. Cleaned coverslips (incubated in ethanol for at least $2 \mathrm{~h}$, rinsed in distilled water and dried) were dipped in 3.5\% PLGA (lactic/ glycolic acid ratio 85:15) (Medisorb, Cincinnati, $\mathrm{OH}$ ) in chloroform (Sigma Aldrich, St. Louis, MO). The dipping and drying cycle was repeated three times. Alternatively, $15 \mu \mathrm{L}$ of 3.5\% PLGA in chloroform was dripped onto clean, round coverslips, using a Hamilton syringe. In both cases, films were dried in a glass dish coated with Sigmacoat (Sigma Aldrich, St. Louis, MO) under a glass lid. Coverslips were dried for $24 \mathrm{~h}$ before cells were seeded. To nucleate mineral, coverslips were mineralized in modified simulated body fluid (MSBF; $141 \mathrm{mM} \mathrm{NaCl}, 4.0 \mathrm{mM} \mathrm{KCl}, 0.5 \mathrm{mM} \mathrm{MgSO}_{4}, 1.0$ $\mathrm{mM} \mathrm{MgCl}{ }_{2}, 1.0 \mathrm{mM} \mathrm{KH_{2 }} \mathrm{PO}_{4}$ ), buffered to $\mathrm{pH} 6.8$ with tris- $\mathrm{HCl}$, and incubated at $37^{\circ} \mathrm{C}$ for 5 days with daily changing of the solutions. All films were kept under vacuum until used. Prior to use in tissue culture, both types of coverslips were sterilized under UV for $15 \mathrm{~min}$, followed by dipping in $70 \%$ ethanol.

\section{Immunofluorescent localization of proteins}

Saponin (Sigma Aldrich, St. Louis, MO), a plant glucoside interacting with cholesterol of the cellular membrane, was used as mild agent for cell membrane permeabilization. Cells were fixed in 2\% paraformaldehyde (EMS, Ft. Washington, PA) for $15 \mathrm{~min}$ at room temperature, washed in PBS, incubated in $0.38 \%$ glycine and $0.27 \% \mathrm{NH}_{4} \mathrm{Cl}$ in $\mathrm{PBS}$ for 10 min, then in blocking buffer (PBS with $1 \%$ BSA, $0.1 \%$ sapo- 
nin, $\mathrm{pH}$ 7.4) for $30 \mathrm{~min}$. All antibodies were diluted in blocking buffer prior to use. Cells were incubated, either for $60 \mathrm{~min}$ at room temperature or overnight at $4^{\circ} \mathrm{C}$, with primary monoclonal antibodies to vinculin (Sigma, St. Louis, $\mathrm{MO})$, a specialized protein of the focal adhesion contact. Cells were then washed three times (10 min each) in blocking buffer, incubated with secondary antibodies Alexa Fluor $488 \mathrm{~F}\left(\mathrm{ab}^{\prime}\right)_{2}$ fragment goat anti-rabbit IgG (Molecular Probes, Eugene, OR) for $30 \mathrm{~min}$, washed $3 \times 10 \mathrm{~min}$ in blocking buffer and $3 \times 10 \mathrm{~min}$ in PBS. Coverslips were mounted in mounting medium (ProLong Antifade Kit, Molecular Probes, Eugene, OR) according to the manufacturer's instructions.

\section{Laser scanning confocal microscopy}

Cells and cell adhesion contacts were observed under a laser scanning confocal microscope. All confocal studies were performed on a Bio Rad Radiance 2000 system (Bio Rad Lab., Hercules, CA) on an inverted microscope Nikon Eclipse TE 300 (Nikon, Melville, NY) using Laser Sharp software (Bio Rad Lab., Hercules, CA). Immunofluorescent images of the cells with visualized cell adhesion contacts were collected and imported into Adobe PhotoShop v.5.5 (Adobe Systems).

\section{Characterization of cell contact distribution}

To characterize the position of the cellular adhesion contacts, the contour of each cell was outlined, and the cell center was calculated and marked using ImagePro software. To quantify the position of each cell adhesion contact within a cell, two measurements were made (Fig. 1): the distance between the cell center and cell adhesion contact, and the distance between the cell center and the edge of the cell. The path from the center to the cell edge followed the same path used to measure the distance between the cell center and the corresponding focal adhesion. The ratio of these measurements was used as a quantitative characteristic of the position of the cell adhesion contact in the cytoplasm.

\section{Colloidal gold preparation and cell motility assay}

Cell motility assays were performed according to Albrecht-Buehler, ${ }^{28}$ with small modifications. ${ }^{29}$ To prepare gold particles, $1.8 \mathrm{~mL}$ of $14.5 \mathrm{mM} \mathrm{AuCl}{ }_{4} \mathrm{H}$ and $6 \mathrm{~mL}$ of 36.5 $\mathrm{mM} \mathrm{Na} \mathrm{CO}_{3}$ solution were added to $11 \mathrm{~mL}$ double distilled water and heated with constant stirring until boiling. Upon boiling, $1.8 \mathrm{~mL}$ of $0.1 \%$ freshly made formaldehyde solution in water was quickly added. The gold particles form almost immediately. A hot $\left(80-90^{\circ} \mathrm{C}\right)$ suspension of gold particles was layered on nonmineralized PLGA and incubated at least 5-6 h. To cover the mineralized PLGA, the colloidal gold suspension was cooled to $50-60^{\circ} \mathrm{C}$, and incubated for at least 5-6 h. After incubation, unattached colloidal gold par-

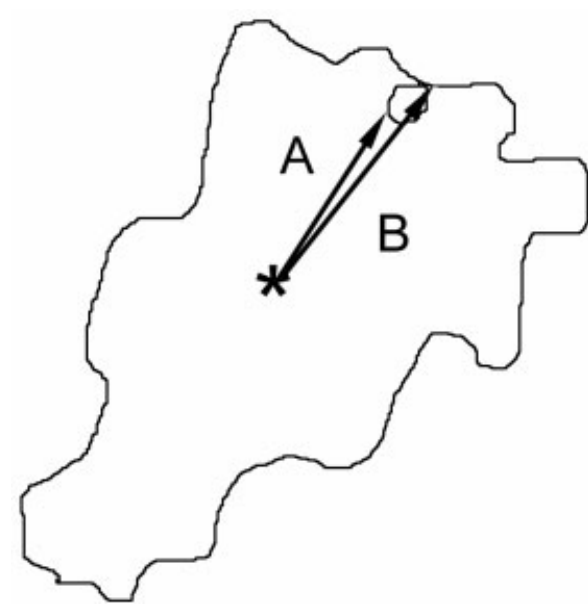

Figure 1. Schematic drawing demonstrating the method used to characterize the position of cell adhesion contacts within a cell. To quantify the difference in cell adhesion contact distribution on different substrates, a contour of each immunofluorescent cell image was made; the center of the cell was calculated and marked (star in schematic), and two measurements, $\mathrm{A}$ and $\mathrm{B}$, were made: $\mathrm{A}$, the distance between the cell center and cell contact (oval in schematic); $\mathrm{B}$, the distance between the cell center and cell edge. The ratio of A to B was used to quantify the position of the contact within the cell.

ticles were gently removed by rinsing with sterile PBS. Coverslips with uniform colloidal gold coverage were selected for analysis by viewing under a light microscope.

\section{Cell preparation for scanning electron microscopy}

Cells on the substrates were rinsed in PBS and fixed in 4\% paraformaldehyde in PBS for $1 \mathrm{~h}$ at room temperature. Fixative was rinsed in PBS $(2 \times 5 \mathrm{~min})$, and dehydrated in ethanol with increasing concentrations, according to standard laboratory protocol for SEM specimen preparation. After the final $100 \%$ ethanol treatment, specimens were transferred to $100 \%$ hexamethyldidilazane (HMDS; Electron Microscopy Sciences, Hatfield, PA), through a graded series of ethanol-HMDS mixtures: 100\% ethanol $\rightarrow$ 2:1 $\rightarrow$ 1:2 $\rightarrow$ $100 \%$ HMDS, 5 min in each solution. After the final step, two changes of $100 \%$ HMDS, 5 min in each were made. After most of the HMDS was removed and just enough solution was left to cover the specimen, specimens were dried under a slightly open lid in a chemical hood overnight.

\section{Statistics}

To compare cell contact distribution on different substrates, three independent experiments were done. In each experiment, three coverslips of each type of substrate were used. Three to ten randomly chosen cells were measured per each type of substrate in each experiment (23 cells on PLGA vs. 18 on mineralized PLGA). The average cell adhesion 

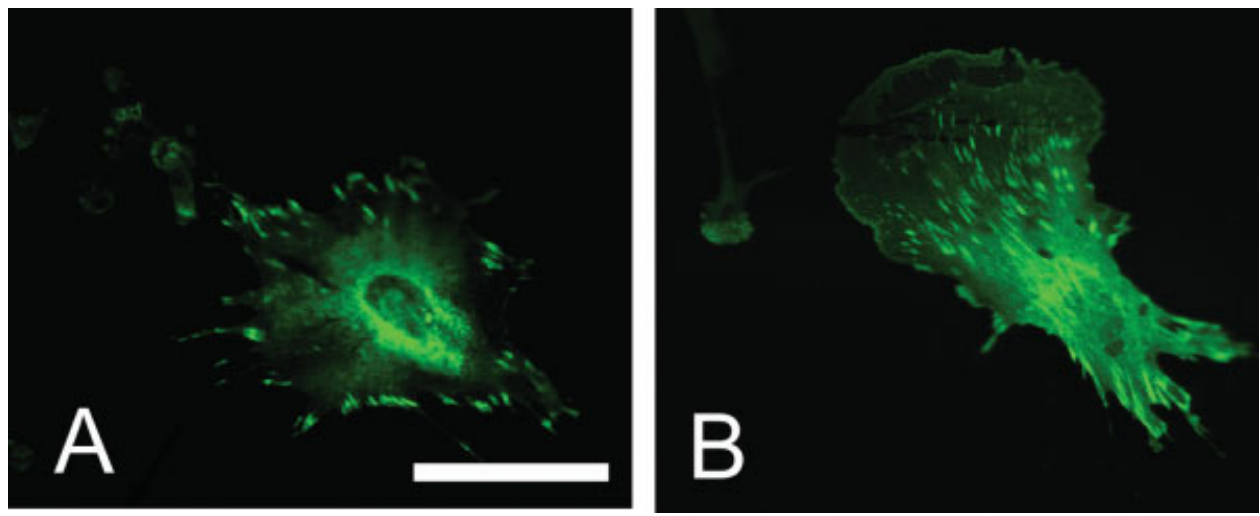

Figure 2. Immunofluorescent localization of cell adhesion contacts using vinculin antibodies. Cell contacts are visible as bright streaks. (A) Contacts on PLGA are localized on the cell periphery. (B) Contacts on mineralized PLGA are distributed throughout the cell surface. Bar: $20 \mu \mathrm{m}$. [Color figure can be viewed in the online issue, which is available at www.interscience. wiley.com.]

contact positions on nonmineralized vs. mineralized substrates (total of 914 for all three experiments on PLGA vs. 1025 on mineralized PLGA) were compared using a Student's $t$-test. The spatial distribution of contacts within each cell was also assessed by dividing each cell into six discrete sections, equidistant from the cell center (see Fig. 4), and determining the percentage of total number of contacts within each region. Across all cells, the average percentage of contacts in each of the six regions was analyzed via a two-way ANOVA for effects of substrate and region. All pairwise multiple comparisons were carried out using Bonferroni post hoc tests.

To quantify the difference in cell migration on nonmineralized vs. mineralized PLGA, and also to compare the temporal pattern of cell motility on these two substrates, cells were seeded on coverslips covered with the two substrates and fixed at different time points: $30 \mathrm{~min}, 45 \mathrm{~min}, 60 \mathrm{~min}, 90$ $\min , 3 \mathrm{~h}, 6 \mathrm{~h}$, and $24 \mathrm{~h}$. Each experiment was repeated three times, and for each time point three coverslips were used. Images of three to five randomly chosen optical fields were taken on each coverslip. Within each field, 5 to 10 cellular paths were measured. The length of each path and the diameter of each cell were measured, and the ratio of these two measurements was used as a phagokinetic index to quantify cell motility. Two-way ANOVA was used to compare the phagokinetic indices as a function of substrate and time, and all pairwise multiple comparisons were carried out using Bonferroni post hoc tests.

\section{RESULTS}

\section{Cell adhesion contacts are distributed differently on nonmineralized and mineralized PLGA}

Cell adhesion contacts of BMSC have a different distribution on PLGA compared with mineralized PLGA. Indirect immunofluorescent localization of vinculin (a protein specific for the cell adhesion contacts), demonstrated that on PLGA, cell adhesion contacts are localized mostly on the periphery of the cells [Fig. 2(A)]. On mineralized substrates, cell adhesion contacts are distributed throughout the cell surface [Fig. 2(B)]. The difference in distribution was statistically significant (Fig. 3, $p<0.001$ ); cell adhesion contacts on mineralized PLGA are significantly closer to the cell center than on PLGA. The average number of contacts per cell was not significantly different on these two substrates: $189 \pm 31$ on PLGA versus $205 \pm 42$ on mineralized PLGA. The spatial distribution of cell adhesion contacts is also different on PLGA and mineralized PLGA (Fig. 4). The contacts on PLGA are distributed near the periphery, mostly in the 4th-6th sections ( $p<0.001$ vs. sections $1-3)$, with the highest percentage of contacts in the 6th section from the cell center $(p<0.001$ vs. sections 4,5$)$. Cell adhesion con-

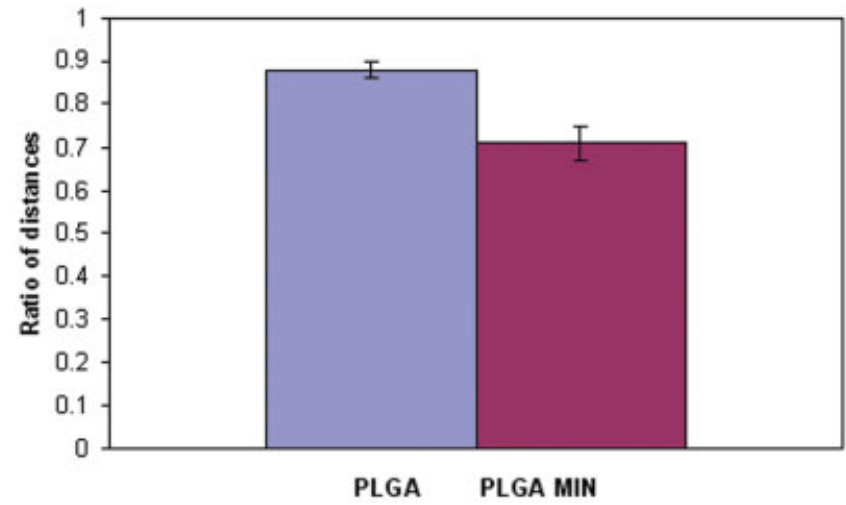

Figure 3. Ratio of the distance from cell center to cell contact vs. the distance from cell center to cell edge for cells on nonmineralized vs. mineralized PLGA. The mean ratio for mineralized PLGA was significantly less than that for PLGA $(p<0.001)$, indicating that cellular contacts were more spatially distributed and significantly closer to the cell center on the mineralized substrates. [Color figure can be viewed in the online issue, which is available at www. interscience.wiley.com.] 


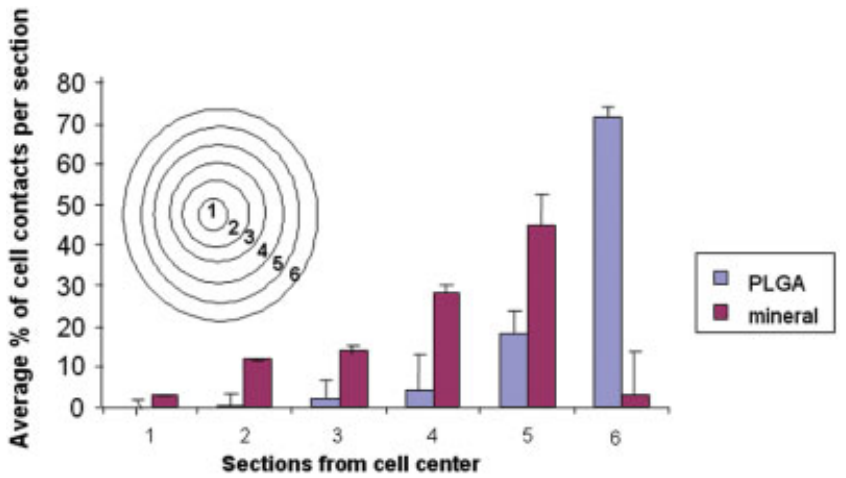

Figure 4. Spatial distribution of cell adhesion contacts on nonmineralized and mineralized PLGA. Cells were divided into six areas, equidistant from the center (see schematic in figure insert). The average percentage of total cell contacts in each area was compared for PLGA and mineralized PLGA. The cellular adhesion contacts on PLGA are distributed near the periphery, mostly in the 4th-6th sections, with the highest percentage of contacts in the 6th section, and almost none in the first three sections. On mineralized PLGA, cellular contacts were present in all sections, with the highest numbers in the 3rd, 4th, and 5th sections. [Color figure can be viewed in the online issue, which is available at www. interscience.wiley.com.]

tacts were mostly absent in the first three sections, which correspond to the area of cytoplasm near the nucleus. On mineralized PLGA, cellular contacts were present in all sections, with the highest numbers in the 3 rd, 4th, and 5th sections ( $p<0.001$ vs. other sections), and the lowest percent of contacts in the 1st and 6th sections ( $p<0.001$ vs. other sections). In sections $3-5$, the percent of contacts on the mineralized substrates was significantly greater than on PLGA $(p<0.001)$, whereas in section 6, the percent of contacts on PLGA was significantly greater $(p<0.001)$

\section{Cells spread and migrate faster on nonmineralized vs. mineralized PLGA}

Thirty minutes after seeding, cells were not completely spread on the surface of either substrate [Fig. 5(A,D)]. Cellular microvillae and membrane extensions were visible on the cell surface. At $45 \mathrm{~min}$, a difference in behavior of cells on the two substrates became visible; cells spread more on PLGA [Fig. 5(B)], compared with the mineralized substrates [Fig. 5(E)]. The surface of the cells on mineralized PLGA demonstrated bubbles and microvillae, compared with the cells on PLGA. The areas of spread cells increased 90 min after cell seeding, and the difference became significant at this time: PLGA, $112 \mu \mathrm{m}^{2}$ [Fig. 5(C)] vs. mineralized PLGA, $44 \mu \mathrm{m}^{2}$ [Fig. 5(F)] $(p<0.05)$.

To test the hypothesis that cells migrate differently on nonmineralized and mineralized surfaces, a colloidal gold assay was used. This assay is based on the ability of colloidal gold particles to weakly attach to a substrate and form a dark gray "carpet" of particles, and on the ability of migrating cells to remove these weakly attached particles leaving behind a clear path, visible with light and scanning electron microscopy (Fig. 6). The shape and length of the cellular paths on mineralized PLGA were shorter and wider [Fig. 6(B)], compared with PLGA [Fig. 6(A)]. Cells migrating on mineralized PLGA coated with colloidal gold were visualized with scanning electron microscopy-cells are presented in red, colloidal gold in yellow and mineral in gray [Fig. $6(\mathrm{C})]$. The presumed direction of cell motility is marked with an arrow. Colloidal gold did not evenly cover the mineral surface, leaving the newly formed conglomerates of mineral uncoated, possibly indicating a difference in charge of the newly
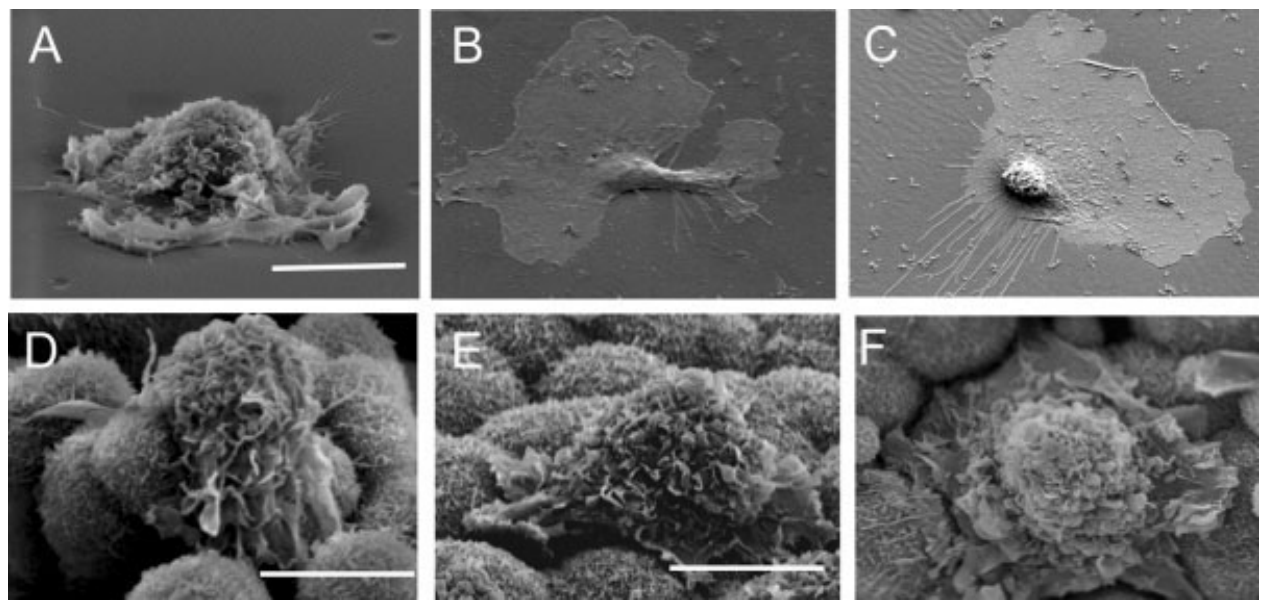

Figure 5. Scanning electron microscopy images of cells seeded on PLGA (A-C), and mineralized PLGA (D-F). Cells were fixed at $30 \mathrm{~min}(\mathrm{~A}, \mathrm{D}), 45 \mathrm{~min}(\mathrm{~B}, \mathrm{E})$, and $90 \mathrm{~min}(\mathrm{C}, \mathrm{F})$ after seeding. Cells spread more on PLGA; mean areas of cells at 90 min on PLGA are $112 \mu \mathrm{m}^{2}$ and for mineralized PLGA are $44 \mu \mathrm{m}^{2}(\mathrm{p}<0.05)$. Bars: (A-D) $5 \mu \mathrm{m} ;(\mathrm{E}, \mathrm{F}) 20 \mu \mathrm{m}$. 

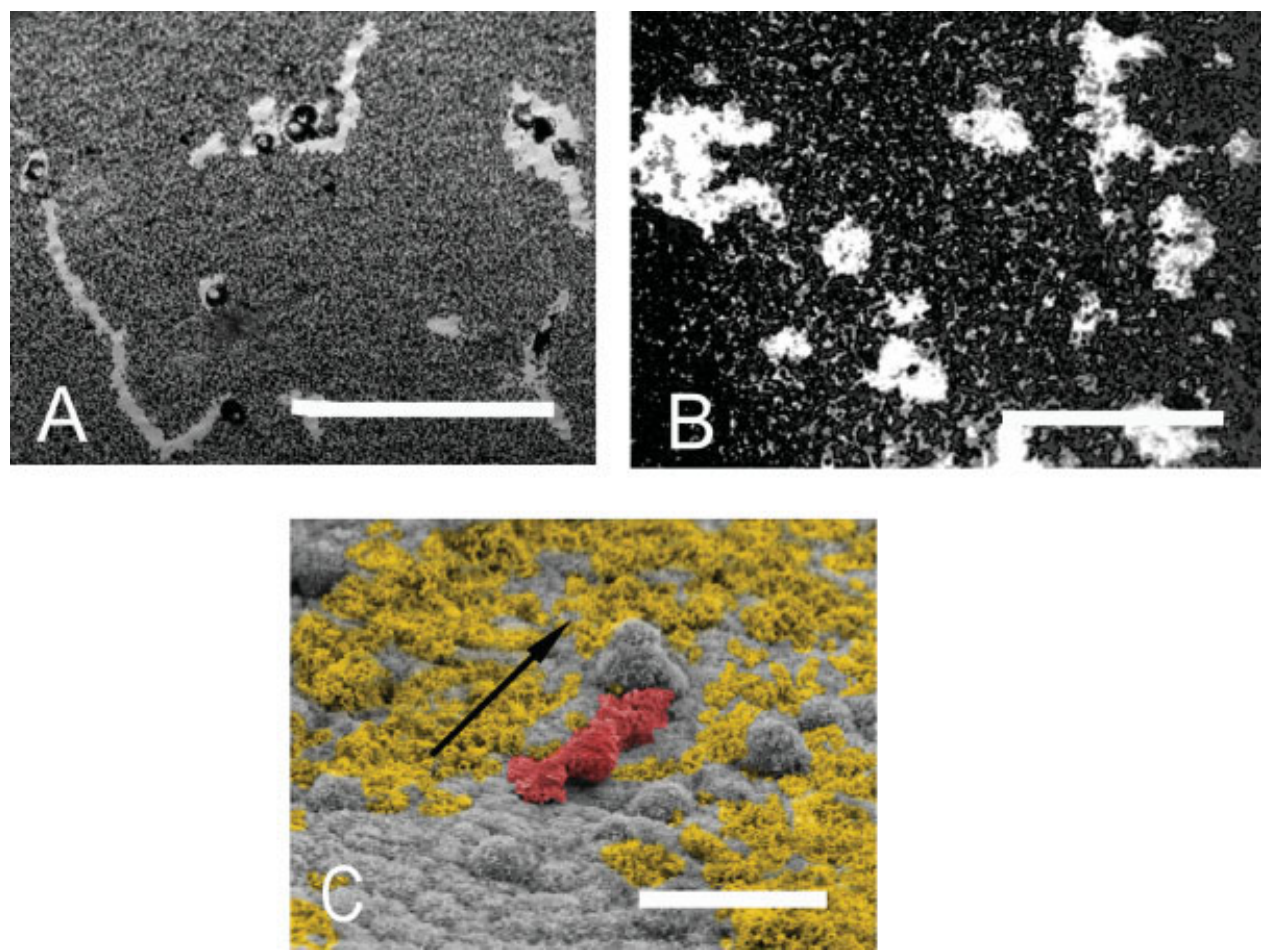

Figure 6. Cell migration characterized by comparing phagokinetic tracks of moving cells on nonmineralized (A) and mineralized PLGA (B,C); (A,B) light microscopy. Colloidal gold is visible as a background for migration of cells. Phagokinetic tracks of migrating cells are visible as white areas. Cells migrate farther during the same period of time on PLGA compared with mineralized PLGA. Bars: $1 \mathrm{~mm}$. (C) Scanning electron microscopy of the cell phagokinetic track on a mineralized substrate. Cells are visible in red, colloidal gold in yellow, mineral in grey. The arrow indicates the presumed direction of cell migration. Bar: $15 \mu \mathrm{m}$. [Color figure can be viewed in the online issue, which is available at www.interscience.wiley.com.]

formed mineral. Cells were able to actively move without complete spreading on the substrate.

Quantitatively, as represented by the phagokinetic indices, cells migrated farther on PLGA compared with mineralized PLGA (Fig. 7). The difference in cell motility was statistically significant at all times greater than $90 \mathrm{~min}(p<0.05)$, when the majority of cells on PLGA became completely spread and practically all cells were actively migrating on both substrates.

\section{DISCUSSION}

The extracellular matrix plays a major role in regulating cell functions, including proliferation, motility, and differentiation. ${ }^{15,16,23,30}$ Cells interact with their ECM through cellular adhesion contacts. One goal of tissue engineering is to synthesize materials as substitutes for the natural ECM as a means of orchestrating changes in cell function. In this study, we compared the distribution of cell contacts on two substrates: PLGA, a synthetic polymer that has been extensively characterized and has a long history of clinical use, and self-mineralized PLGA, which has enhanced mechanical and osteoconductive properties. ${ }^{7,11}$ By using a new approach to quantify the position of cell adhe- sion contacts, we demonstrated that on PLGA, cell adhesion contacts are present by the periphery of the cell surface, whereas on mineralized substrates, cell adhesion contacts are distributed throughout cellular surfaces and, on average, are located closer to the nucleus. Based on the position of the contacts relative to the cell center, we propose that BMSCs express different adhesion contacts on nonmineralized and mineralized PLGA; PLGA mostly has focal adhesion contacts, whereas cells on mineralized PLGA predominantly express fibrillar contacts.

Several types of cell contacts, with different positions on the cell surface, protein composition, and function have been described in fibroblasts: focal complexes, focal adhesion contacts, fibrillar contacts, and 3D contacts. ${ }^{31-33}$ Cell adhesion contacts are dynamic formations; each type of contact can be gradually replaced by a different type of contact as microenvironmental conditions change. ${ }^{14,16,33}$ Focal complexes are responsible for cell attachment. They are formed at the end of lamellae, do not have connection to actin fibers, and can transform into focal adhesion contacts. ${ }^{14}$ Focal adhesion contacts are large, located near the cell periphery, connected to actin bundles, and responsible for strong attachment to a substrate. ${ }^{14,32,33,34}$ Fibrillar contacts form under the influence of tension in actin 


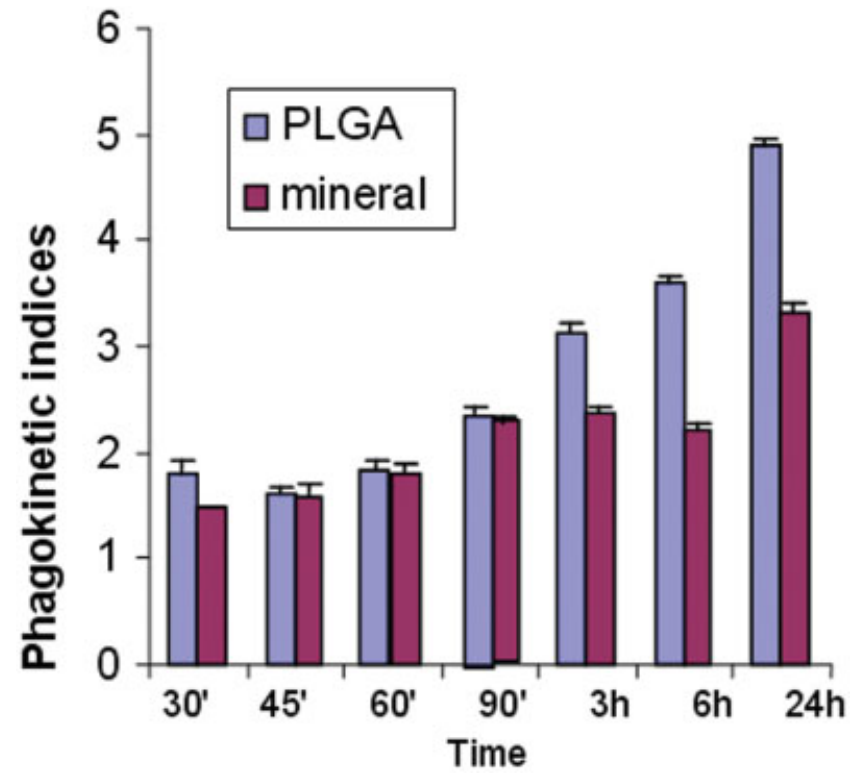

Figure 7. Cell motility characterized by comparing the phagokinetic index of motile cells on nonmineralized and mineralized PLGA. Cells were seeded on nonmineralized and mineralized PLGA and fixed at $30 \mathrm{~min}, 40 \mathrm{~min}, 60 \mathrm{~min}$, $90 \mathrm{~min}, 3 \mathrm{~h}, 6 \mathrm{~h}$, and $24 \mathrm{~h}$. The ratio of the length of the cell path to the diameter of the cell was used as a quantitative metric of cell motility and is called a phagokinetic index. The phagokinetic assays demonstrated that cells migrate farther on PLGA compared with mineralized PLGA at all times greater than $90 \mathrm{~min}$. Error bars represent standard error of the means. [Color figure can be viewed in the online issue, which is available at www.interscience.wiley.com.]

bundles from the focal adhesion contacts, interact with fibronectin, are present in the central part of the cell, and promote extracellular matrix formation. ${ }^{14}$ Fibrillar contacts can mature into 3D contacts. ${ }^{33}$ Based on our data on the distribution of cellular adhesion contacts, we propose that cells on PLGA mostly contain focal adhesion contacts, whereas cells on mineralized PLGA have a high level of fibrillar contacts.

Substrate properties could influence the formation of fibrillar contacts. Self-mineralization of a polymeric substrate may therefore influence cell contact maturation by affecting the formation of fibrillar contacts. It is known that strong attachment to the underlying substrate and immobile fibronectin prevents $\alpha_{5} \beta_{1}$ integrin motion in the plane of the membrane and formation of fibrillar contacts. ${ }^{32}$ On the basis of this fact, we propose that fibronectin could be less flexibly attached to PLGA compared with mineralized PLGA. The higher level of fibrillar contacts on mineralized PLGA could also reflect more active formation of the extracellular matrix on this substrate, compared with PLGA, a concept supported by in vivo data. ${ }^{11}$

Cell motility was observed on both substrates, but cells spread faster and move farther on PLGA compared with mineralized PLGA. Our hypothesis that mineralization influences maturation of cell-adhesion contacts can be applicable to cell migration also. Recent data demonstrating that the level of cell migration can correlate with the level of proteins specific to fibrillar cell contacts indirectly support this hypothesis. ${ }^{35}$

Substrate properties could also influence the retraction step of cell migration by influencing the structure and function of ligands (e.g. fibronectin, vitronectin) attaching to the synthetic matrix. ${ }^{17,36}$ Ligands not only attach differently to substrates with different properties, ${ }^{37}$ but also change their composition and conformation depending on substrate properties such as topography, chemical composition, and mechanical properties. ${ }^{38-43}$ When cell-substrate adhesion increases, as is the case with mineralized PLGA, ${ }^{11}$ cells become less capable of retracting from the substrate, and so cell motility decreases. Moreover, the mineral layer creates a composite which has greater stiffness than the native polymer. ${ }^{7}$ Cells generate more traction force and develop a broader and flatter morphology on stiff substrates compared with soft, but equally adhesive substrates, and fibroblasts migrate from soft to hard surfaces. ${ }^{40}$ We therefore propose that mineralization of a polymer provides stronger cell adhesion, but also more difficult retraction of the cell adhesions and, as a result, reduced motility.

In summary, self-mineralization of a polymer substrate regulates the maturation of cell adhesion contacts and, as a result, influences cell motility, and differentiation. The predominant expression of fibrillar contacts on mineralized PLGA could be the initial mechanism for the enhanced osteoconductive properties of mineralized substrates.

\section{References}

1. Muschler GF, Nakamoto C, Griffith LG. Engineering principles of clinical cell-based tissue engineering. J Bone Joint Surg Am 2004;86:1541-1558.

2. Griffith LG. Emerging design principles in biomaterials and scaffolds for tissue engineering. Ann NY Acad Sci 2002;961:8395.

3. Karageorgiou ML, Fajardo R, Snyder B, Shindle-Patil V, Zichen L, Kaplan D, Langer R, Vunjak-Novakovic G. Bone tissue engineering using human mesenchymal stem cells: Effect of scaffold material and medium flow. Ann Biomed Eng 2004;32: 112-122.

4. Kaufmann E, Ducheyne P, Shapiro IM. Effect of varying physical properties of porous, surface modified bioactive glass $45 \mathrm{~S} 5$ on osteoblast proliferation and maturation. J Biomed Mater Res A 2000;52:783-796.

5. Kim H-W, Georgiou G, Knowles JC, Koh Y-H, Kim H-E. Calcium phosphates and glass composite coatings on zirconia for enhanced biocompatibility. Biomaterials 2004;25:4203-4213.

6. Griffith LG. Polymeric biomaterials. Acta Mater 2000;48:263277.

7. Murphy WL, Kohn DH, Mooney DJ. Growth of continuous bonelike mineral within porous poly(lactide-co-glycolide) scaffolds in vitro. J Biomed Mater Res 2000;50:50-58. 
8. Radin S, Falaize S, Lee MH, Ducheyne P. In vitro bioactivity and degradation behavior of silica xerogels intended as controlled release materials. Biomaterials 2002;23:3113-3122.

9. Radin S, El-Bassyouni G, Vresilovic EJ, Schepers E, Ducheyne $P$. In vivo tissue response to resorbable silica xerogels as controlled-release materials. Biomaterials 2005;26:1043-1052.

10. Baldwin SP, Saltzman MW. Materials for protein delivery in tissue engineering. Adv Drug Deliv Rev 1998;33(1/2):71-86.

11. Kohn DH, Shin K, Hong SI, Jayasuriya AC, Leonova EV, Rosello RA, Krebsbach PH. Self-assembled mineral scaffolds as model systems for biomineralization and tissue engineering. In: Landis WJ, Sodek J, editors. Proceedings of the Eight International Conference on the Chemistry and Biology of Mineralized Tissues. Toronto: University of Toronto Press; 2005. pp 216-219.

12. Burridge K, Chrzanowska-Wodnicka M. Focal adhesions, contractility, and signaling. Annu Rev Cell Dev Biol 1996;12:463518.

13. Geiger B, Bershadsky A. Assembly and mechanosensory function of focal contacts. Curr Opin Cell Biol 2001;13:584-592.

14. Geiger B, Bershadsky A, Pankov R, Yamada KM. Transmembrane crosstalk between the extracellular matrix-cytoskeleton crosstalk. Nat Rev Mol Cell Biol 2001;2:793-805.

15. Geiger B. Cell biology. Encounters in space. Science 2001;294: 1661-1663.

16. Cukierman E, Pankov R, Stevens DR, Yamada KM. Taking cell-matrix adhesions to the third dimension. Science 2001;294: $1708-1712$.

17. Gumbiner BM. Cell adhesion: The molecular basis of tissue architecture and morphogenesis. Cell 1996;84:345-357.

18. Zamir E, Geiger B. Molecular complexity and dynamics of cell-matrix adhesions. J Cell Sci 2001;114 (Part 20):3583-3590.

19. Hynes RO. Integrins: Versatility, modulation, and signaling in cell adhesion. Cell 1992;69:11-25.

20. Wary KK, Mainiero F, Isakoff SJ, Marcantonio EE, Giancotti FG. The adaptor protein Shc couples a class of integrins to the control of cell cycle progression. Cell 1996;87:733-743.

21. Giancotti FG. A structural view of integrin activation and signaling. Dev Cell 2003;4:149-151.

22. Tu Y, Wu S, Shi X, Chen K, Wu C. Migfilin and Mig-2 link focal adhesions to filamin and the actin cytoskeleton and function in cell shape modulation. Cell 2003;113:37-47.

23. Chen CS, Tan J, Tien J. Mechanotransduction at cell-matrix and cell-cell contacts. Annu Rev Biomed Eng 2004;6:275-302.

24. Gronthos S, Simmons PJ. The biology and application of human bone marrow stromal cell precursors. J Hematother 1996; 5:15-23.

25. Krebsbach PH, Kuznetsov SA, Bianco P, Robey PG. Bone marrow stromal cells: Characterization and clinical application. Crit Rev Oral Biol Med 1999;10:165-181.

26. Krebsbach PH, Robey PG. Dental and skeletal stem cells: Potential cellular therapeutics for craniofacial regeneration. J Dent Educ 2002;66:766-773.

27. Harrison J, Pattanawong S, Forsythe JS, Gross KA, Nisbet DR, Beh H, Scott TF, Trounson AO, Mollard R. Colonization and maintenance of murine embryonic stem cells on poly( $\alpha$-hydroxy esters). Biomaterials 2004;25:4963-4970.

28. Albrecht-Buehler G. The phagokinetic tracks of $3 \mathrm{~T} 3$ cells. Cell 1977;11:395-404

29. Scott WN, McCool K, Nelson J. Improved method for the production of gold colloid monolayers for use in the phagokinetic track assay for cell motility. Anal Biochem 2000;287:343344.

30. Zamir E, Katz M, Posen Y, Erez N, Yamada KM, Katz BZ, Lin S, Lin DC, Bershadsky A, Kam Z. Dynamics and segregation of cell-matrix adhesions in cultured fibroblasts. Nat Cell Biol 2000;2:191-196.

31. Yamada KM, Pankov R, Cukierman E. Dimensions and dynamics in integrin function. Braz J Med Biol Res 2003;36:959966.

32. Pankov R, Cukierman E, Katz B-Z, Matsumoto K, Lin DC, Lin $S$, Hahn C, Yamada KM. Integrin dynamics and matrix assembly: Tensin-dependent translocation of $\alpha_{5} \beta_{1}$ integrins promotes early fibronectin fibrillogenesis. J Cell Biol 2000;148:1075-1090.

33. Cukierman E, Pankov R, Yamada K. Cell interactions with three-dimensional matrices. Curr Opin Cell Biol 2002;14:633639.

34. Adams JC. Regulation of protrusive and contractive cell-matrix contacts. J Cell Sci 2002;115:257-265.

35. Kondo S, Kagami S, Urushihara M, Kitamura A, Shimizu M, Strutz F, Muller GA, Kuroda Y. Transforming growth factor- $\beta 1$ stimulates collagen matrix remodeling through increased adhesive and contractive potential by human renal fibroblasts. Biochim Biophys Acta 2004;1693:91-100.

36. Clark EA, Brugge JS. Integrins and signal transduction pathways: The road taken. Science 1995;268:233-239.

37. Dewez J-L, Doren A, Schneider Y-J, Rouxhet PG. Competitive adsorption of proteins: Key of the relationship between substratum surface properties and adhesion of epithelial cells. Biomaterials 1999;20:547-559.

38. Ma Z, Gao C, Gong Y, Shen J. Cartilage tissue engineering PLLA scaffold with surface immobilized collagen and basic fibroblast growth factor. Biomaterials 2005;26:1253-1259.

39. Ma Z, Gao C, Gong Y, Shen J. Chondrocyte behaviors on poly-L-lactic acid (PLLA) membranes containing hydroxyl, amide or carboxyl groups. Biomaterials 2003;24:3725-3730.

40. Lo CM, Wang HB, Dembo M, Wang YL. Cell movement is guided by the rigidity of the substrate. Biophys J 2000;79:144152.

41. Li W-J, Danielson KG, Alexander PG, Tuan RS. Biological response of chondrocytes cultured in three-dimensional nanofibrous poly(å-caprolactone) scaffolds. J Biomed Mater Res A 2003;67:1105-1114

42. Lee SJ, Khang G, Lee YM, Lee HB. The effect of surface wettability on induction and growth of neurites from the PC-12 cell on a polymer surface. J Colloid Interface Sci 2003;259:228235.

43. Lee JH, Lee JW, Khang G, Lee HB. Interaction of cells on chargeable functional group gradient surfaces. Biomaterials 1997;18:351-358. 